\title{
O estágio supervisionado de Letras sob lentes complexo-discursivas: a cultura de ensinar (re)visitada
}

\author{
Cátia Veneziano Pitombeira \\ PUC-Campinas/FATEC Praia Grande \\ Lucas Rodrigues Lopes \\ UNICAMP/FATEC Itapira e Mogi Mirim
}

\begin{abstract}
Resumo
O presente trabalho visa trazer reflexões sobre o componente curricular obrigatório do curso de Letras - estágio supervisionado - sob lentes discursivas e viés da Complexidade. O olhar proporcionado, ora pelas lentes discursivas ora pelo viés da Complexidade, aponta que os contextos sociais são marcados pela multiculturalidade, pertinentes para a compreensão da necessidade de mudança face às demandas da sociedade hipermoderna em que o homem precisa ser pensado e (re)interpretado nas diversas esferas.
\end{abstract}

Palavras-chave: complexidade, discurso, professor, estágio supervisionado

\begin{abstract}
This paper aims to reflect on the several voices emerging from a curricular discipline called "Under-supervision Teaching" in a Letters course from a discursive-complex perspective. This perspective, including both discourse and Complexity, points to the notion that social contexts are identified by multiculturality, and this helps the understanding that there is a need for change in light of the demands of hypermodern society which calls for new thinking about human beings in various dimensions.
\end{abstract}

Key-words: complexity, discourse, professor, under-supervision teaching

\section{INTRODUÇÃO}

A escolha de ser professor é um ato que (de)marca territórios e identidades, pois, com base na cultura e na história de vida de cada pessoa, (re)incide na subjetividade e considera práticas, valores, modos de atuar estabelecidos e consolidados pela própria instituição escolar. Pensando a respeito dos muitos caminhos, trajetos e territórios (per)corridos por alunos de um curso de licenciatura em Letras, focalizamos, neste estudo, o aluno que participa do estágio supervisionado. Sob a ótica dos territórios diversos, afirmaríamos que o pano de fundo do estágio supervisionado é uma arena movediça, escorregadia e repleta de tensões. Sobretudo, para o estagiário, estar entre a prática de 
ensino e a teoria pode ser o momento de considerar as partes de um todo, as idas e vindas, e ter de lidar com as (des)ordens, com o (des)controle e com a imprevisível tarefa de (re)traçar rotas e cursos ao ensinar. A complementaridade dos opostos a partir do diálogo existente entre eles é ilustrada por Sommerman (2009, p. 66):

Os opostos se articulam e se unem sem se anularem. A unidade construída vai além da simples justaposição dos contrários. Os opostos interagem e formam uma unidade, configurando outro nível de realidade. Os opostos não desaparecem. Ao deixarem de interagir, voltam ao nível anterior, ao nível das oposições. Os opostos radicais, como a clausura e a abertura, não se superam. Eles convivem.

Espaço movediço, uma vez que a sala de aula é apenas um possível desenho de todas as possíveis ramificações que podem vir a desdobrar. Escorregadio devido à quebra e às rupturas emergentes entre o conteúdo e a forma, visto que vivemos tempos hipermodernos que (re)desenham novas formas de ensinar e buscam, na dicotomia novovelho, tecnologias e (ex)tensões para ensinar línguas. Tensões, porque as instituições escolares se constituem de regras que, aparentemente, causam silenciamentos e calam reflexões que (des)constroem um paradigma a ser seguido e estabelece polaridades entre o real e o ideal.

\section{DAS ESCOLHAS TEÓRICAS}

Pretendemos trabalhar sob as lentes da Complexidade com possíveis entrelaçamentos com as teorias do discurso. Para isso, recorreremos a Edgar Morin (2000) a fim de que possamos dar conta de um viés complexo diante do ato docente como fenômeno concreto no estágio supervisionado de um curso de Letras. Posteriormente, valer-nos-emos de conceitos discursivos bakhtinianos, para (re)pensar a prática de ensino dos alunos desse curso, uma vez que muitos ingressam em cursos de licenciaturas já com experiências docentes.

É sob o viés da Complexidade que percebemos que a escola caminha em dissonância da sociedade contemporânea, isto porque o paradigma tradicional de ensino vive hoje uma crise caracterizada por Marcondes (1999, p.15) como "uma mudança conceitual, ou uma mudança de visão de mundo, consequência de uma insatisfação com os modelos de ensino anteriormente predominantes de explicação”. O mundo, fora dos muros da escola, reflete uma realidade na qual tudo e todos se conectam, vive-se em rede em que capturar consiste em ser capturado. Morin (2000, p. 17) nos alerta que "o especialista torna-se ignorante de tudo aquilo que não concerne à sua disciplina". Também, para o 
teórico francês (2000, p.45), "o parcelamento e compartimentalização dos saberes impedem apreender o que é tecido junto".

A fim de que possamos entender o momento sócio-histórico cultural pelo qual passamos, tomamos a égide de tempos hipermodernos, que é definida por Lipovetsky (2007, p. 25-26) como:

Hipermodernidade: uma sociedade liberal, caracterizada pelo movimento, pela fluidez, pela flexibilidade; indiferente como nunca antes se foi aos grandes princípios estruturantes da modernidade, que precisaram adaptar-se ao ritmo hipermoderno para não desaparecer $[. .$.

Desse modo, se a sociedade hodierna é constituída pela dúvida e pela incerteza, o profissional que ensina línguas terá de se apropriar do pensamento complexo ora para agir em favor de sua própria formação ora pela formação de seu aluno. Isso se efetuaria pela busca do viés complexo emergente do/no interrogar, questionar, duvidar, pensar e repensar a sua própria formação e o seu papel formador na escola que atua(rá). Além disso, valendo-nos da natureza dialógica da linguagem e do que é proposto por Bakhtin (2006, p. 114), percebemos que "a enunciação é o produto da interação de dois indivíduos socialmente organizados". A esse respeito, Lopes (2010, p. 15) afirma que "toda palavra tem duas faces. Ela procede de alguém, como pelo fato de que ela se dirige para alguém". De tal modo, ao perceber e compreender o significado (linguístico) do discurso, o ouvinte ocupa simultaneamente uma posição responsiva. Ele pode concordar ou discordar dele, completá-lo, aplicá-lo e prepará-lo para usar.

Ainda, com olhos voltados para o viés da Complexidade, trabalhamos num princípio dialógico que permita o vínculo de elementos/pensamentos antagônicos e que propiciem o entendimento de uma recursão organizativa, auxiliando o (futuro) professor a entender que somos ao mesmo tempo produto e produtores de saberes e da cultura escolar; e que auxilie no entendimento do princípio hologramático, percebendo que o todo está nas partes e a parte está no todo. Por isso, compreender o outro, compreender a si e ao mundo exige consciência da complexidade humana. Uma nova formação passa pela compreensão de que a complexidade

[...] é ao mesmo tempo meio e fim da comunicação humana. O planeta necessita, em todos os sentidos, de compreensões mútuas. Dada a importância da educação para a compreensão, em todos os níveis educativos e, em todas as idades, o desenvolvimento da compreensão necessita de reforma planetária das mentalidades; esta deve ser a tarefa da educação do futuro (MORIN, 2000, p. 104)

Diante dessas afirmações morinianas, buscamos um possível entrelaçamento com o que é apresentado por Lopes (2010, p. 26) no qual para o autor "toda palavra pressupõe um 
outro, a quem a fala deve ser ajustada, de quem antecipa reações e mobiliza planos. $O$ outro é também outro discurso e outros textos". Então, a partir disso, conseguimos estender o pano de fundo do estágio supervisionado, um ato de comunicação, constituindo de um caráter social e é o produto de trocas, atentando para o fato de que haverá sempre um contexto que é o conjunto de condições de vida de determinada comunidade linguística.

Por isso, tecer fios de conhecimentos práticos intercalando às linhas de conhecimentos teóricos, construiria, então, uma colcha que busque a complementação da formação do aluno: objetivo do estágio supervisionado em um curso de licenciatura em Letras. É o momento no qual matizes sociais, profissionais e culturais deve(ria)m se misturar na tentativa de fazer emergir um quadro que se apresenta(ria) no momento em que os alunos adentram diferentes espaços escolares, privados ou públicos, para cumprirem a carga horária obrigatória.

Com base em documentos oficiais, percebemos a emergência de um possível contraste estabelecido entre o professor real $\mathrm{X}$ o professor ideal. $\mathrm{E}$ buscaremos (des)construir o ideário da atuação de alunos no estágio supervisionado de um curso de Letras. Partiremos das resoluções do Conselho Nacional de Educação (CNE) que apresentam as expectativas em relação ao estágio supervisionado e, posteriormente, as (inter)relações complexo-discursivas, que aproximarão o aluno da realidade em que atuará.

\section{ESTÁGIO SUPERVISIONADO NA LICENCIATURA EM LETRAS}

O curso de Formação de Professores da Educação Básica, segundo a CNE/CP $n^{0} 2 / 2002$, prevê a articulação teoria-prática garantida em sua carga horária total. O curso de Letras tem por requisito 2800 (duas mil e oitocentas) horas, das quais 400 (quatrocentas) horas referem-se à prática como componente curricular, vivenciadas ao longo do curso; 400 (quatrocentas) horas de estágio curricular supervisionado a partir do início da segunda metade do curso; 1800 (mil e oitocentas) horas de aulas para os conteúdos curriculares de natureza científico-cultural e 200 (duzentas) horas para outras formas de atividades acadêmico-científico-culturais.

No entanto, a circularidade entre as experiências vividas e a reflexão crítica da prática interpretada e reinterpretada acompanhará o profissional por toda a docência, conforme complementa Filatro (2004, p. 26):

Conceitos como educação continuada ou permanente, aprendizagem por toda a vida e sociedade do conhecimento, nos fazem crer que a autoeducação e o autodesenvolvimento não são mais opções de uma parcela específica da 
sociedade cuja vocação para o aprender pavimenta um caminho de progresso e enriquecimento pessoal.

Percebemos que os documentos oficiais de educação não descrevem exatamente como deve ser realizado o estágio supervisionado, simplesmente apresentam a carga horária sem descrever o conteúdo que deve ser observado e analisado em sala de aula. Essa falta de detalhes conduz o aluno de Letras de instituições diferentes a observarem objetos diferentes. Acreditamos que o objeto a ser observado /analisado deveria ser o mesmo, o olhar é que tem de ser diferente.

O estágio supervisionado, objeto de estudo neste artigo, descrito no parecer CNE/CP n ${ }^{\circ} 21 / 2001($ p. 5) pretende:

[...] oferecer ao futuro licenciado um conhecimento do real em situação de trabalho, isto é, diretamente em unidades escolares dos sistemas de ensino. É também um momento para se verificar e provar (em si e no outro) a realização das competências exigidas na prática profissional e exigíveis dos formandos, especialmente quanto à regência.

Além da tentativa de (re)aproximar a teoria e a prática da sala de aula, a CNE/CP 2/2002 ainda prescreve a necessidade de o estágio supervisionado ser avaliado tanto pela instituição de ensino do aluno de Letras, bem como pela escola em que realiza essa atividade do componente curricular:

O estágio curricular supervisionado, definido por lei, a ser realizado em escola de educação básica, e respeitado o regime de colaboração entre os sistemas de ensino, deve ser desenvolvido a partir do início da segunda metade do curso e ser avaliado conjuntamente pela escola formadora e a escola campo de estágio. (p. 6)

Neste aspecto, torna-se possível identificar que falta estabelecer uma relação entre os dois atores desse processo: aluno de Letras e o professor da aula observada ou até mesmo a escola, porque a análise da observação reportada em forma de relatório, muitas vezes não é lida ou conhecida pelo professor observado ou pela própria direção da escola promotora do estágio.

\section{UMA LEITURA CRÍTICA DO ESTÁGIO SUPERVISIONADO SOB LENTES COMPLEXO-DISCURSIVAS}

Ancorando-nos nos dizeres de Morin (2000, p. 25) de que "o que nos salva é que, felizmente, temos uma vida dupla, uma vida tripla; não somos só cientistas, também somos pessoas em particular, também somos cidadãos, também somos seres com convicção metafísica ou religiosa", desse modo, podemos pensar que nos constituímos na relação 
com o outro. Esse outro se constitui no/do outro humano, outro discursivo e do outro presente no acabamento estético de um texto, ou ainda, outro como memória, até no/do outro como devir.

Assim, pensamos o estágio supervisionado em Letras como o lugar propício à produção de conhecimento, uma vez que a proposta dele seria a ligação entre os seres e as coisas. Ainda, sob esse enfoque, vale a pena ressaltar a necessidade de aprimoramento constante do professor; condição esta que permite estabelecer um contínuo espiral que tocam pontos que se entrelaçam a partir do viés da complexidade, a vida e o ato de ensinar, seguindo o que é proposto por Moraes (2007, p. 21):

\begin{abstract}
Acreditamos que a complexidade como fator constitutivo da realidade da vida é, portanto, inerente à ação do sujeito, ao seu pensamento e ao objeto com que trabalha. Enfim, é inerente à dinâmica da vida. Sendo um fator constitutivo da vida, isto significa que a complexidade, como expressão de uma tessitura comum, é o que possibilita a vida e favorece o desenvolvimento da inteligência, do pensamento e a evolução dos sistemas vivos. Como fator constitutivo da vida, significa que ela rege os acontecimentos, as ações, os eventos e os processos e, desta forma, ontológica e epistemologicamente falando, ela não permite separar ser/realidade, sujeito/objeto, educador e educando, objetividade/subjetividade, sujeito/cultura e sociedade, bem como retirar do sujeito docente/discente suas qualidades mais sensíveis.
\end{abstract}

Por isso, apontaríamos a reforma do pensamento que emerge no estágio supervisionado em Letras. Essa reforma seria uma mudança que conscientizaria seus participantes de que fazem parte de uma imbricada engrenagem que constitui todos como (re)agentes. Relação essa que orientaria essas partes-todo. Buscamos, em Morin (1996, p.275 apud Cava 2006), uma melhor definição e salientamos que:

\begin{abstract}
Aprendemos muito bem a separar. (...) Nosso pensamento é disjuntivo e, além disso, redutor: buscamos a explicação de um todo através da constituição de suas partes. Queremos eliminar o problema da complexidade. Este é um obstáculo profundo, pois obedece à fixação a uma forma de pensamento que se impõe em nossa mente desde a infância, que se desenvolve na escola, na universidade, e se incrusta na especialização; e o mundo dos experts e dos especialistas maneja cada vez mais nossas sociedades. É esse, segundo ele, o núcleo do seu empreendimento reflexivo. (...) Morin nos instiga (...) a enfrentarmos a complexidade de nosso mundo, a olharmos para nós mesmos, com nossas fragilidades e medos, com um olhar profundo, olhando-nos e pensando-nos de maneira complexa, múltipla e singular (p. 8).
\end{abstract}

Continuando, pensaríamos numa engrenagem como construção de sentidos de modo interconectado e complexo: um processo que une pensamentos originários de contextos sociais tão conturbados e multiculturais. 
Ao propormos um encontro entre Morin e Bakhtin, tínhamos em mente a reforma do que se pensa a respeito dos estágios, uma vez que, frequentemente, eles configuram-se em atividades distantes da realidade concreta das escolas. Entrelaçando as bases teóricas, desse modo propondo a (des)construção do conhecimento e de certas metodologias já ultrapassadas no que tange ao ensino de línguas, podemos recorrer aos estudos bakhtinianos a fim de que possamos repensar questões educacionais, uma vez que Bakhtin traz à baila a dimensão dialógica da linguagem quando afirma que somos nós humanos que produzimos enunciados e que o enunciado marca nossa existência. Esse aspecto é recorrente em Morin, pois o teórico francês afirma que a constituição do homem se dá a partir de diferentes esferas. Sendo assim, só pode ser interpretado se visto pelo viés biológico, psíquico, social, afetivo e racional. Além disso, há sempre planos econômicos, sociológicos e religiosos que desenham sua atuação. Tendo em mente essa característica do homem terreno, atentamos para as condições de produção dos discursos e das práticas sociais no estágio supervisionado, porque a instituição escolar é constituída e atravessada por múltiplos territórios no conjunto de fazeres, saberes, normas, proibições, ideias e valores.

Assim, compreendemos que o estágio pode, sim, ser um momento de tensão, porque estamos sempre num movimento de ir além do excedente propiciado pela visão. Mas, é preciso (re)pensar a condição de quem ensina há anos, porque compomo-nos outro e compomos outros. Somos (in)acabados, somos espaços abertos e o por vir. Por isso, a língua que se ensina é organismo vivo; exige de quem ensina e aprende interação das partes-(re)agentes.

\section{CONCLUSÃO}

Nossas reflexões emergem nas/das diversas crises pelas quais os sistemas educacionais vêm passando. (Re)dimensionar a formação de professores de línguas, tendo como ponto de partida os estágios supervisionados, torna-se uma questão crucial. Quando trouxemos à discussão uma intersecção do viés da Complexidade e de uma visão discursiva, pensamos na emergência de um diálogo que ate novos nós e desate os velhos diante de concepções de sujeito, subjetividade e construção de conhecimento.

Com base em nossa experiência como professores em cursos de Letras, apontamos que são recorrentes as vozes que, nas salas de orientações de estágios supervisionados, ainda relatam uma visão positivista do ser humano que se reflete nas práticas pedagógicas. O pensar complexo-discursivo remete à compreensão de que não existem possibilidades de 
transmissão de conhecimento único, verdadeiro e imutável. Além disso, a relação professor-aluno mediada pelo conhecimento é, por si só, uma relação entre subjetividades complexas e em permanente construção do real. Maturana e Varela (2005, p. 264) sintetizam bem a ideia de (re)pensar a formação de professores de línguas, a partir dos estágios supervisionados, quando afirmam que:

\footnotetext{
[...] nossos 'pontos cegos' cognitivos são continuamente renovados e não vemos que não vemos, não percebemos que ignoramos. Só quando alguma interação nos tira do óbvio - por exemplo, quando somos bruscamente transportados a um meio cultural diferente -, e nos permitimos refletir, é que nos damos conta da imensa quantidade de relações que consideramos como garantidas. (Maturana e Varela, 2005, p. 264)
}

Para concluir, podemos dizer que o professor em formação estará sempre no entremeio. Ele é o responsável por perturbar a agitação do ambiente escolar. É ele quem traz na mala novas invenções que conectam partes-todo e todo-partes: suas ações didáticas, os companheiros de sala de aula e outros componentes do ambiente de aprendizagem. Além disso, essas perturbações, que podem ser provenientes de agentes externos, desencadeariam diferentes mudanças estruturais no organismo vivo que é a sala de aula.

\section{REFERÊNCIAS}

BAKHTIN, M. Estética da criação verbal. 4. ed. São Paulo: Martins Fontes, 2006.

BEHRENS, M. A.; OLIARI, A. L. T. A evolução dos paradigmas na educação: do pensamento científico tradicional à complexidade. Revista Diálogo Educacional. Universidade Católica do Paraná. Vol.7, n. 2, p.53-56/dez 2007.

CAVA, P. P. Pensando em direção a uma "pedagogia da complexidade”. UniRevista, v.1, $\mathrm{n}^{\circ} 2,2006$.

FILATRO, A. Design instrucional contextualizado: educação e tecnologia. Senac, 2004.

LIPOVETSKY, G. A felicidade paradoxal: ensaio sobre a sociedade de hiperconsumo. São Paulo, Companhia das Letras, 2007.

LOPES, L.R.. O blogueiro e suas práticas - corpos carnavalizados e interações multifacetadas. 2010. 122f. Dissertação (Mestrado em Linguística) Universidade Federal de São Carlos: São Carlos.

MARCONDES, D. A crise de paradigmas e o surgimento da Modernidade. In: BRANDÃO, Z. A crise dos paradigmas e a educação. Cortez, 1999. 
MORAES, M.C. A formação do educador a partir da complexidade e da transdisciplinaridade. Revista Diálogo Educacional. Universidade Católica do Paraná. Vol.7, n. 22, p.13-38/dez 2007.

MORIN, E. Ciência com consciência. Rio de Janeiro: Bertrand Brasil, 2000.

MORIN, E. Introdução ao pensamento complexo. Sulina, 2007.

MATURANA, H.; VARELA, F. A árvore do conhecimento: as bases biológicas da compreensão humana. São Paulo: Palas Athena, 5a . ed., 2005.

SOMMERMAN, A. et al. O que há entre teoria e prática? Há o mundo da vida. In: Santos, A.; Sommerman, A. (Org.). Complexidade e transdisciplinariedade: em busca da totalidade perdida. Conceitos e práticas na educação. Porto Alegre: Sulina, 2009.

\section{OS AUTORES}

Cátia Veneziano Pitombeira é doutora e mestre em Linguística Aplicada e Estudos da Linguagem pela PUC-SP na linha de pesquisa de Linguagem, Tecnologia e Educação. É licenciada e bacharel em Letras: Português/Inglês e Tradução e Interpretação pela Faculdade Ibero-americana (1992). Possui experiência na área de Letras com ênfase em Língua Inglesa no ensino superior, atuando principalmente nos seguintes temas: ensino e aprendizagem de línguas, inglês para fins específicos, tecnologia aplicada ao ensino e à formação docente, desenho de material didático, linguística aplicada, metodologia de ensino e estágio supervisionado. Atualmente, é docente da graduação da PUC Campinas e FATEC Praia Grande.

E-mail: catiavp@hotmail.com

Lucas Rodrigues Lopes é licenciado/bacharel em Letras Português/Inglês pela Pontifícia Universidade Católica de Campinas (2007), mestre em Linguística, área de concentração Estudos Linguísticos, linha de pesquisa - Linguagem e Discurso - pela Universidade Federal de São Carlos (UFSCar) (2010). Atualmente, é professor de nível superior tecnológico de língua inglesa dos cursos de Análise e Desenvolvimento de Sistemas, Gestão da Produção Industrial, Gestão da Tecnologia da Informação e Mecatrônica nas Faculdades de Tecnologia (FATEC) das cidades de Mogi Mirim e Itapira e desenvolve pesquisa de doutorado em Linguística Aplicada, área de concentração Linguagem e Sociedade, linha de pesquisa Linguagens, Culturas e Identidades, na Universidade Estadual de Campinas (UNICAMP). E-mail: lukelopes@yahoo.com.br 